\title{
Machinability performance of Al-NiTi and Al-NiTi-nano SiC composites with parametric optimization using GSA
}

\begin{abstract}
The manuscript discusses the abrasive water jet machining (AWJM) of Al-NiTi and $\mathrm{Al}-$ NiTi-nano SiC composites to understand the influences and the effect of each parameter and to indentify optimal combination of AWJM parameters. The experiments are planned and conducted based on L27 orthogonal array. Pressure, standoff distance, and transverse feed rate are considered as input parameters; surface roughness and kerf angle are considered as output parameters. Gravitational search algorithm (GSA) is employed to identify the best possible combination of AWJM parameters. Regression model is used to develop the surface roughness and kerf angle model for $\mathrm{Al}-\mathrm{NiTi}$ and Al-NiTi-nano SiC composites. The developed mathematical model is used as fitness function in GSA. It is found from the result of GSA that the optimal value for surface roughness of Al-NiTi composite is set at pressure $176 \mathrm{kPa}$, standoff distance $1 \mathrm{~mm}$, and transverse feed $20 \mathrm{~mm} / \mathrm{min}$ and for Al-NiTi-nano SiC composite is set at pressure $180 \mathrm{kPa}$, standoff distance $1.1 \mathrm{~mm}$, and transverse feed 20 $\mathrm{mm} / \mathrm{min}$. Similarly, for kerf angle, the optimal value for Al-NiTi composite is set at pressure 260, standoff distance $1 \mathrm{~mm}$, and transverse feed $20 \mathrm{~mm} / \mathrm{min}$ and for Al-NiTi-nano SiC composite is set at pressure $255 \mathrm{kPa}$, standoff distance $1 \mathrm{~mm}$, and transverse feed 20 $\mathrm{mm} / \mathrm{min}$. Analysis of variance is also performed to understand the effect of each input parameter on output response.
\end{abstract}

Keyword: Al-NiTi; Al-NiTi-nano SiC; AWJM; Surface roughness; Kerf angle; GSA; Regression; Mechanical properties 